\title{
Territory quality and male dominance in Tropidurus torquatus (Squamata, Tropiduridae)
}

\author{
Tiana Kohlsdorf ${ }^{1}$, Joana M. Ribeiro and Carlos A. Navas \\ Departamento de Fisiologia, Instituto de Biociências, Universidade de São Paulo. Rua do Matão, Trav. 14, 321, \\ 05508-900. São Paulo, SP, Brazil. E-mails: tiana@usp.br, jobiousp@hotmail.com, navas@usp.br. \\ 1 Present Address: Departamento de Biologia, FFCLRP, Universidade de São Paulo. Av. Bandeirantes, 3900, \\ 14040-901, Ribeirão Preto, SP, Brazil.
}

\begin{abstract}
Territory quality and male dominance in Tropidurus torquatus (Squamata, Tropiduridae). In territorial species, females are often attracted by high-quality territories, which are expected to be owned by males that successfully won competition with other males. Because morphological and behavioral traits frequently influence males' combat success, these parameters may be used by females to assess the male (and associated territory) quality. In the present study, we tested the hypothesis that organismal traits in dominant males of the lizard Tropidurus torquatus are associated with the quality of the territory owned. After characterizing the territories occupied, we used a discriminant analysis to test if morphological and behavioral traits of the dominant male predict the quality of the territory owned. High-quality territories were characterized by a larger number of refuges, shorter distances among shelters and a well-defined harem, in comparison with low-quality territories. Organismal traits predicted with $100 \%$ accuracy the type of the territory owned: high-quality territories were associated with larger males that had longer heads, while males occupying lowquality territories exhibited more head displays, traveled larger distances and ran slightly slower than those associated with high-quality territories. We discuss possible implications of territory quality and male traits for reproductive success in Tropidurus torquatus.
\end{abstract}

Keywords: Squamata, tropiduridae, Tropidurus torquatus, sexual selection, morphology, behavior, territory quality.

\section{Introduction}

In territorial species, a positive correlation between morphological characteristics of territorial males and those defining territory quality is frequently observed (Price 1984,

Received 3 May 2006.

Accepted 19 November 2006.

Distributed December 2006.
Roithmair 1994, Pough et al. 1998, Bart and Earnst 1999, Candolin and Voigt 2001, Huyghe et al. 2005; but see Lappin and Husak 2005, Husak et al. 2006). This correlation suggests that territorial males are exposed to sexual selection, and that they are likely to exhibit greater variation in mating success than females (Pough et al. 1998, Lappin and Husak 2005). Some males within a population are better fit to establish and hold a high-quality territory 
because territorial defense might expose individuals to increased predation risk and requires an investment in both energy and time. Therefore, in species where females choose males or the territories they defend, the best males tend to occupy the best territories (Candolin and Voigt 2001), and are more likely to be preferred by females. These males acquire more reproductive partners, and the females choosing them enhance their fitness due to a number of factors associated with high-quality territories, for example improved food availability (Hews 1990, 1993, Kwiatkowski and Sullivan 2002), number of refuges against predators and of egg laying sites (Calsbeek and Sinervo 2002a), and, in the case of vertebrate ectotherms that thermoregulate behaviorally, opportunity for thermoregulation (Calsbeek and Sinervo 2002a,b). Female choice of the best males in the best territories, therefore, increases the fitness of the couple.

The lizard Tropidurus torquatus is highly territorial (Pinto 1999), and males often exhibit larger home range areas than those of females or juveniles (Giaretta 1996). Females visit or are residents to male territories; the groups of females associated with a dominant male are called harems and can be quantified by focal studies. Males are usually larger and heavier than females (Vitt and Goldberg 1983, Giaretta 1996, Wiederhecker et al. 2002), so that they can be told apart easily in the field. This study tests the hypothesis that morphological and behavioral traits are associated with territory quality in lizards, specifically investigating if a group of variables defining the morphometric and physiological profiles of male lizards could properly discriminate a category of territory quality ("high-quality” versus "low-quality”).

\section{Material and Methods}

Information about territory quality was obtained in the field, whereas data on morphological and performance traits of males were collected in the lab. The individuals included in the present study belong to a population at Parque Continental, Osasco (São Paulo state, Brazil; Figure 1A). This is a residential area characterized by several houses with large backyards, separated by walls or fences. The specific place where the focal observations were performed was a private area surrounded by high walls containing a small inhabited house and a large backyard (approximately $200 \mathrm{~m}^{2}$ ) with several piles of fallen trunks and rocks (Figure 1B). After the observation periods (see below), we collected dominant males by noose and marked them dorsally with nail painting. We transported the lizards to the lab in cloth bags and maintained them in terrariums with permanent access to water. Lamps were provided for behavioral thermoregulation. Mean room temperature was $27^{\circ} \mathrm{C}$ and light-dark cycle was $12: 12$ hours. We kept individuals in captivity in maximum for five consecutive days for performance experiments, and then returned them exactly to the same place where they were captured. We fed them live crickets after performance experiments. We conducted field observations and measurements in the lab once a month, from September to December 2002, always between 09:00 $\mathrm{h}$ and 17:00 h.

\section{Characterization of Territory and Male Behavior}

Tropidurus torquatus tend to be territorial and exhibit a social organization in which females choose territories within the range of a resident male. Males tend to be faithful to a territory. Females are free to wonder among male territories, but it is quite frequent to observe the same females associated with the same males. The territories used in this study were placed near urban areas (i.e. in walls or fences of residential areas or fallen trunks, rocks and bushes of backyards, in the city of Osasco, São Paulo state, Brazil; Figure 1A). Reproductive dominant males were evident because of their size and signaling behaviors, 

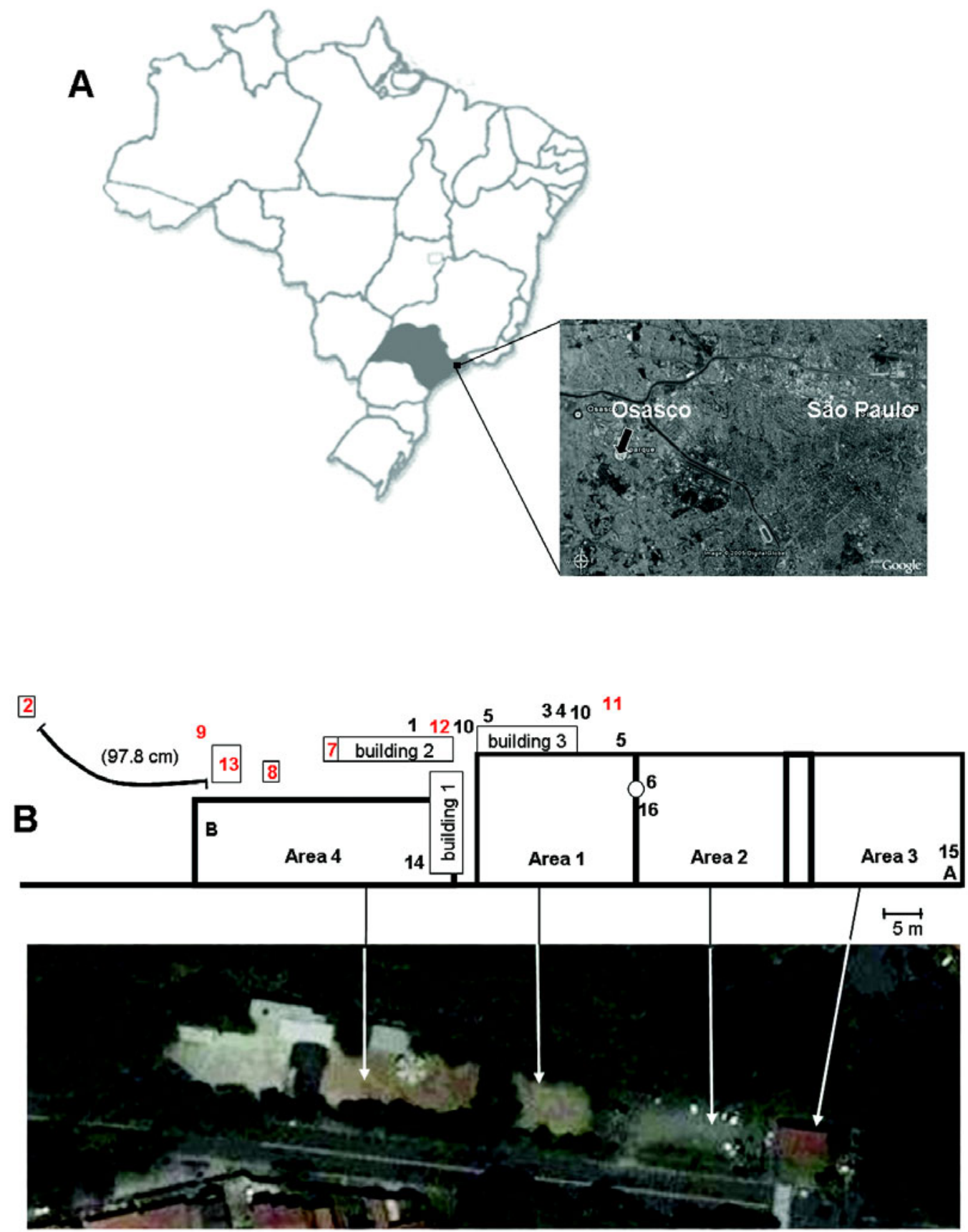

Figure 1 - (A) General location of the site where field work was performed. B) Map and aerial view of the site where field observations were performed: black numbers indicate males associated with low-quality territories, red numbers correspond to males occupying high-quality territories. The repeated individuals (5 and 10) were males that changed their territories during the months that this study was conducted. The images in this figure were obtained from the Google Earth ${ }^{\circledR}$ service. 
such as intense head bobbing and aggressive interactions (e.g. chasing). After identifying a dominant male, we conducted 30 minutes of focal observations and registered in a tape recorder the total number of individuals associated with the harem (these included females, small males and juveniles) and the estimated distance traveled by the dominant male. Females were easily distinguished from small males because of their smaller heads relative to body size and thicker trunks, and because they were less prone to perform visual signaling. Signaling with different parts of the body is common in Tropidurus and other lizard taxa (Cooper 1989, Olsson 2001), and these cues are used for assessment of rivals and partners (Jansson et al. 2005). Some common types of signaling include head bobbing (e.g. McMann 1993, Macedonia et al. 1994, Martins and Lamont 1998, Paterson 2002) and tail whipping (e.g. Ord et al. 2001, Watt and Joss 2003). Accordingly, we also counted the number of head and tail displays performed by males during the focal observation period.

We classified territories as "high-quality" or "low-quality" based on observations of female behavior (e.g. fidelity to a territory), number of refuges available, and distance between refuges. We emphasized refuge distribution and number because a large number of shelter sites within a territory probably favors harem holding and prevent associated females to search for extraterritorial copulations. Furthermore, refuge number is an important component of territory quality in other territorial lizards such as Uta stansburiana (Calsbeek and Sinervo 2002b, Calsbeek et al. 2002) and Ctenophorus ornatus (LeBas 2001). We included in the data set other variables related to the physical traits of the territory, namely estimated height (in case of a pile of rocks, fallen trunks or constructions as building walls), estimated area (based on a scale plot drown by hand in which an observer registered the farther points reached by a given male), and average of hours of sunshine (i.e., affected by shade patterns according to localization; for example, if half of the plot had sunshine during the day, estimated hours of sunshine would be 4 hours). We also classified territory attractiveness to females using a category based on whether or not harems were well defined. Well-defined territories were those occupied and defended by a single dominant male in which most of the individuals in the territory interacted only among themselves. Undefined territories were those with more than one male playing the dominant role, and where most of the females and juveniles interacted with more than one adult male. Our classification based on each individual episode of focal observation (i.e. each time the harem was observed for 30 minutes) was satisfactory in that all harems classified as 'well-defined' maintained this status during the following observations (a similar situation was observed for undefined territories). However, we acknowledge that individuals from different territories were likely to interact when focal observations were not being conducted, and that under some circumstances assessing the exact number of individuals associated to a territory was not possible. The amount of refuges, therefore, was considered as a more quantifiable indicator of territory quality. Refuge number seems important given the behavior of the species, in which males signal danger to females, and are last to flee when a disturbance occurs. We observed a total of 18 dominant males, from which 16 were captured and measured in the lab (Figure 1B).

\section{Morphometry}

We measured external morphometric traits in each captured male using digital calipers to the nearest $0.01 \mathrm{~mm}$. The same person (JMR) performed all measurements. Morphometric traits included snout-vent length (SVL), tail length, hind limb length (femur + tibia + foot lengths), forelimb length (humerus + radius + hand lengths), and head dimensions (length, width and height). We also measured body mass 
in a digital balance to the nearest of $0.01 \mathrm{~g}$, to assess changes in male condition along the months of observation.

\section{Sprint Speeds}

We assessed sprint speeds using a racetrack with five sets of photocells at intervals of $50 \mathrm{~cm}$ connected to a computer, using customized software and stimulating animals to run by hand. The experimental temperature was $35^{\circ} \mathrm{C}$, as field temperatures in $T$. torquatus are close to $34^{\circ} \mathrm{C}$ and those selected in a thermal gradient are close to $36^{\circ} \mathrm{C}$ (Kohlsdorf and Navas 2006). We discarded races in which individuals ran against the walls of the racetrack or turned back before the end of the track, in this case conducting new trials an hour later. We recorded three runs for each individual every time it was captured, in order to assess the maximum sprint speed each male was able to attain. From all runs recorded for each individual, we used the fastest reading as an index of maximum sprint speed. In order to verify the repeatability of individual variation in sprint speed, we correlated (using SPSS version 12.0 for PC) the best and second-best performances of each individual, regardless of the day on which each occurred, following Peterson and Husak (2006).

\section{Statistical Analyses}

In order to eliminate effects of body size on other morphometric variables, we calculated residuals of tail, forelimb and hindlimb lengths and head dimensions against SVL and used those in the statistical analyses. The discriminant analysis was performed in SPSS 12.0 for PC. The database regarding male condition included both morphometric (SVL and residuals of tail and limbs lengths and head dimensions), behavioral (tail and head signaling, estimated traveled distance) and exercise physiology (maximum sprint speed) traits. To further analyze the impact of each variable on the capacity of discrimination between high-quality and low-quality territories, we also applied a stepwise approach to the discriminant analysis. This procedure was based on the standard canonical coefficients obtained in the discriminant analysis, and consisted of removing variables from the discriminant analysis one at the time, from lowest to greatest canonical coefficients, until we observed a minimum of $75 \%$ of cases correctly classified in the original groups. In this stepwise approach, a cumulative exclusion sequence was adopted, i.e., a second variable was removed after the first one was withdrawn, the third variable was removed after the first and second variables were excluded, and so on.

\section{Results}

A total of 18 dominant males were observed in the field, from which 16 were also captured and measured in the lab. Therefore, all data analyzed and discussed in the present study refer to these 16 individuals that were quantified both in focal observations in the field and in performance and morphometry in the lab. Our criteria lead to the split of observed territories into two unambiguous groups (Table 1). The territories considered as low-quality exhibited less and more distant refuges and exhibited fewer individuals strictly associated with the dominant male, in comparison with high-quality territories. However, territories categorized in such manner did not differ in total area (Table 1; $t$-test, $\mathrm{P}=0.265, t=1.61, \mathrm{DF}=14)$, estimated height (Table 1 ; $t$-test, $\mathrm{P}=0.707, t=-0.38$, $\mathrm{DF}=14$ ), or amount of sunshine hours (Table 1; $t$-test, $\mathrm{P}=0.092, t=1.81, \mathrm{DF}=14)$. Some harems were unmistakably better defined than others (e.g., females and juveniles in low-quality territories interacted with two or more dominant males). However, the number of individuals in undefined territories was sometimes hard to assess (see methods), and we failed to detect differences to this regard between high-quality and low-quality territories (Table 1 ; $t$-test, $\mathrm{P}=0.123, t=-1.64, \mathrm{DF}=14$ ). 
Table 1 - Characteristics of the territories; mean \pm standard error are presented.

\begin{tabular}{lcc}
\hline Trait & High-quality territory & Low-quality territory \\
\hline Harem & defined & undefined \\
Number of refuges & $23.00 \pm 7.59$ & $1.39 \pm 0.29$ \\
Average distance between refuges (m) & $0.66 \pm 0.30$ & $1.96 \pm 0.50$ \\
Number of individuals & $6.79 \pm 0.97$ & $6.00 \pm 0.78$ \\
Area $\left(\mathrm{m}^{2}\right)$ & $5.07 \pm 2.01$ & $7.04 \pm 2.90$ \\
Maximum height (m) & $2.54 \pm 0.97$ & $2.11 \pm 0.65$ \\
\% of sunlight & $42.14 \pm 5.55$ & $47.00 \pm 4.36$ \\
\hline
\end{tabular}

Maximal sprint performance was variable among adult Tropidurus males but significantly repeatable within each individual. The Pearson Correlation Coefficient $(r)$ between each individual's best and second-best sprint speed was $0.545(\mathrm{P}=0.029, \mathrm{~N}=16)$.

The multivariate analysis based on morphological and behavioral traits discriminated with $100 \%$ accuracy dominant males belonging to high-quality or low-quality territories (discriminant analyses: eigenvalue $=19.071$, canonical correlation $=0.975 ; 100 \%$ of original grouped cases correctly classified). Males associated with high-quality territories were longer, and exhibited proportionally bigger (longer and wider) heads and longer tails, hindlimbs and forelimbs. They traveled shorter distances and performed more tail movements (Tables 2 and $3)$. In contrast, dominant males associated with low-quality territories exhibited narrower but higher heads and performed more headknobbing displays (Tables 2 and 3). They also exhibited slightly slower sprint speeds than males owning high-quality territories (Tables 2 and 3). The multivariate analysis including all sources of information, therefore, was very successful at discriminating individuals according to territory quality. This discrimination, however, was produced in the context of subtle differences that did not become evident when variables were considered individually in parametric tests. Only number of tail movements was clearly distinguishable between the high- quality and low-quality groups ( $t$-test, $\mathrm{P}=0.002$, $t=-3.740, \mathrm{DF}=14)$.

Removing the four variables with the lowest canonical coefficients ("residuals of head width", "residuals of hindlimb length", "residuals of tail length" and "amount of tail movements") did not affect the percentage of individuals correctly classified in their original groups (100\% discrimination), but changed slightly the canonical correlation coefficient (from 0.975 to 0.933 ) and had clear effects on the eigenvalue (an indicator of the statistical power of the discriminant analysis that changed from 19.071 to 6.725 ). The power of the discriminant analysis decreased sharply after the removal of "maximal sprint speed". In this case, $92.9 \%$ of cases were correctly classified, the eigenvalue decreased to 1.911 and the canonical correlation coefficient dropped to 0.810 . Similar patterns were observed after the exclusion of the variables "distance traveled" (86.7\% of cases correctly classified; eigenvalue $=1.438$, canonical correlation coefficient $=0.768$ ) and “residuals of forelimb" (85.7\% of cases correctly classified; eigenvalue $=0.678$, canonical correlation coefficient $=0.636$ ). The discrimination dropped below the established minimum of $75 \%$ when SVL was removed from the analysis (64.3\% of cases correctly classified; eigenvalue $=0.342$, canonical correlation $=$ 0.505). Overall, these multiple tests indicate that the major parameters contributing for a correct classification of males into a category of 
Table 2 - Characteristics of the dominant males; mean \pm standard error are presented.

\begin{tabular}{lcc}
\hline Trait & High-quality territory & Low-quality territory \\
\hline Sprint speed $\left(\mathrm{m}^{-\mathrm{s}^{-1}}\right)$ & $3.20 \pm 0.21$ & $3.19 \pm 0.16$ \\
Snout-vent length $(\mathrm{cm})$ & $11.79 \pm 0.43$ & $11.36 \pm 0.31$ \\
Tail length $(\mathrm{cm})$ & $17.42 \pm 0.71$ & $13.62 \pm 1.49$ \\
Forelimb length $(\mathrm{cm})$ & $5.77 \pm 0.16$ & $5.60 \pm 0.09$ \\
Hind limb length $(\mathrm{cm})$ & $9.48 \pm 0.40$ & $9.02 \pm 0.25$ \\
Head length $(\mathrm{cm})$ & $3.62 \pm 0.10$ & $3.51 \pm 0.13$ \\
Head width $(\mathrm{cm})$ & $2.32 \pm 0.09$ & $2.21 \pm 0.05$ \\
Head height $(\mathrm{cm})$ & $1.40 \pm 0.07$ & $1.38 \pm 0.06$ \\
Number of head movements & $13.45 \pm 1.77$ & $14.21 \pm 2.53$ \\
Number of tail movements & $1.09 \pm 0.32$ & - \\
Estimated traveled distance $(\mathrm{m})$ & $8.29 \pm 1.69$ & $9.77 \pm 4.16$ \\
\hline
\end{tabular}

Table 3 - Standardized canonical discriminant function coefficients; negative values predict males owning low-quality territories, positive values predict males owning high-quality territories.

\begin{tabular}{lc}
\hline Trait & Canonical coefficient \\
\hline Residuals of head length & 8.212 \\
Snout-vent length & 5.896 \\
Estimated traveled distance & 4.135 \\
Residuals of forelimb length & 3.564 \\
Residuals of tail length & 0.940 \\
Residuals of head width & 0.443 \\
Number of head movements & -7.840 \\
Residuals of head height & -7.796 \\
Sprint speed & -4.065 \\
Number of tail movements & -0.913 \\
Residuals of hindlimb length & -0.895 \\
\hline
\end{tabular}

territory quality are body size ("SVL"), head shape ("residuals of head length" and "residuals of head height"), and behavioral signaling (“amount of head movements").

\section{Discussion}

The present study clearly supports the idea that territory quality (particularly in terms of number of refuges available) in Tropidurus torquatus relates to the size, shape, and behavioral characteristics of the dominant males. It is possible, however, that other trends remained undetected as a consequence of difficulties assessing the exact values of some variables in our study, for example the number of individuals in a territory. Although males in high-quality territories are only slightly larger than those in low quality territories, body size emerges as an important parameter. Larger males have better territories and, perhaps as a consequence, exhibit better ability to hold 
harems. Indeed, female preference for larger males has been reported in various lizard species (Cooper and Vitt 1993, Wikelski et al. 1996, Calsbeek and Sinervo 2002b), although there are also several lizard species where females' choice is not observed (Olsson and Madsen 1995, Hamilton and Sullivan 2005). Female $T$. torquatus can be actually attracted by the high-quality territories that are secured by larger males (e.g. Hews 1993, Calsbeek and Sinervo 2002a), or may assess territory quality based directly on the morphometric parameters of a resident male, such as body size and head dimensions (e.g. Pough et al. 1998, Calsbeek and Sinervo 2002b). Large male lizards may own territories with enhanced prey density (Reaney and Whiting 2003), refuge density and opportunity for thermoregulation (Calsbeek and Sinervo 2002a, Calsbeek et al. 2002). Female choice experiments will be useful to determine whether or not females exhibit preferences for certain male morphologies independently of the quality of the territories held. This sort of experiments is relevant because it is also possible that the evolutionary processes shaping male morphology in $T$. torquatus have been influenced also by intrasexual competition (Hews 1990, Ord et al. 2001). Larger males may outstand in fighting ability (Hews 1990) because reptile combat success often correlates positively with body size (Cooper and Vitt 1987, 1993, Olsson 1992, 1993, Rodda 1992, Zucker and Murray 1996, Schuett 1997, Kratochvíl and Frynta 2002; but see Lappin and Husak 2005). Interestingly, Lappin and Husak (2005) observed that in males of Crotaphytus collaris the mating success seems associated with bite forces, which is probably related to fighting ability. A following step from our study would be measuring bite forces and fighting ability in dominant males of Tropidurus torquatus, in order to verify if morphological differences and reproductive success are also related to combat efficiency and the capacity to retain the best territories in this species.
Male $T$. torquatus holding the best territories are also slightly better runners. This pattern, although subtle and supported only by the multivariate test, agrees with studies focusing on organismal performance and social dominance in other iguanids (Garland et al. 1990, Robson and Miles 2000, Miles et al. 2001, Perry et al. 2004). Locomotor performance seems to be related with several aspects that determine fitness, including reproductive success (Garland and Losos 1994, Perry et al. 2004), and both endurance and sprint speed seem to be positive predictors of the outcome of combats or encounters between lizard males (Robson and Miles 2000, Perry et al. 2004). Contrasting with dominant males holding high-quality territories, males from low-quality territories exhibit more head displays (despite their smaller heads), travel larger distances, and hold territories in which refuges are scarce and spaced apart. Additionally, the harems associated with those territories tend to be undefined, so that males interact with competitors more often. We argue that individuals in these territories are more exposed to intruding males, and this might explain the need for increased signaling. These males are more exposed to agonistic interactions, and the increased number of displays might reduce the risk of actually engaging into physical combats with other males (Ord et al. 2001).

Finally, we point out to the need of studying in the future the number of offspring sired by males from high-quality and low-quality territories. This is important because the success of a male defending a high-quality territory does not necessarily indicate its genetic reproductive success. Multiple mating (LeBas 2001) and sperm competition (Olsson and Madsen 1998, Pough et al. 1998, Calsbeek and Sinervo 2002b) have been observed in several vertebrates.

\section{Acknowledgements}

The authors are extremely thankful to M. B. Grizante, G. E. Kaneto, R. B. Nunes and F. B. 
Oliveira for field and lab assistance. This study was supported by a FAPESP Doctoral Fellowship to TK (00/06662-5) and FAPESP research grants to CAN (95/11542-7 and 03/ 01577-8). Animals were collected under IBAMA permission (022/02-RAN).

\section{References}

Bart, J. and S. L. Earnst. 1999. Relative importance of male and territory quality in pairing success of male rock ptarmigan (Lagopus mutus). Behavioral Ecology and Sociobiology 45: 355-359.

Calsbeek, R. and B. Sinervo. 2002a. An experimental test of the ideal despotic distribution. Journal of Animal Ecology 71: 513-523.

Calsbeek, R. and B. Sinervo. 2002b. Uncoupling direct and indirect components of female choice in the wild. Proceedings of the National Academy of Sciences 99: 14897-14902.

Calsbeek, R., S. H. Alonzo, K. Zamudio, and B. Sinervo. 2002. Sexual selection and alternative mating behaviors generate demographic stochasticity in small populations. Proceedings of the Royal Society London B 269: 157-164.

Candolin, U. and H. R. Voigt. 2001. Correlation between male size and territory quality: consequence of male competition or predation susceptibility? Oikos 95: $225-230$.

Cooper, W. E. 1989. Absence of prey odor discrimination in agamid and iguanid lizards in applicator tests. Copeia 1989: 472-478.

Cooper W. E. and L. J. Vitt. 1987. Deferred agonistic behavior in a long-lived scincid lizard, Eumeces laticeps. Oecologia 72: 321-326.

Cooper, W. E. and L. J. Vitt. 1993. Female mate choice of large male broad-headed skinks. Animal Behaviour 45: 683-693.

Garland, T. Jr. and J. B. Losos. 1994. Ecological morphology of locomotor performance in squamate reptiles. Pp. 240-302 in P. C. Wainwright and S. M. Reilly (eds.), Ecological Morphology - integrative organismal biology. Chicago, University of Chicago Press.

Garland, T. Jr., E. Hankins and R. B. Huey. 1990. Locomotor capacity and social dominance in male lizards. Functional Ecology 1990: 243-250.

Giaretta, A. A. 1996. Tropidurus torquatus (NCN). Home Range. Herpetological Review 27: 80-81.

Hamilton, P. S. and B. K. Sullivan. 2005. Female mate attraction in ornate tree lizards, Urosaurus ornatus: a multivariate approach. Animal Behaviour 69: 219224.

Hews, D. K. 1990. Examining hypotheses generated by filed measures of sexual selection on male lizards, Uta palmeri. Evolution 44: 1956-1966.

Hews, D. K. 1993. Food resources affect female distribution and male mating opportunities in the iguanian lizard Uta palmeri. Animal Behaviour 46: 279-291.

Husak, J. F., A. K. Lappin, S. F. Fox and J. A. LemosEspinal. 2006. Bite-force performance predicts dominance in male Venerable Collared Lizards (Crotaphytus antiquus). Copeia 2006: 301-306.

Huyghe, K., B. Vanhooydonck, H. Scheers, M. MolinaBorja, and R. Van Damme. 2005. Morphology, performance and fighting capacity in male lizards, Gallotia galloti. Functional Ecology 19: 800-807.

Jansson, N., T. Uller and M. Olsson. 2005. Female dragons, Ctenophorus pictus, do not prefer scent from unrelated mates. Australian Journal of Zoology 53: 279-282.

Kohlsdorf, T. and C. A. Navas. 2006. Ecological constraints on the evolutionary association between field and preferred temperatures in Tropidurinae lizards. Evolutionary Ecology 20: 549-564.

Kratochvíl, L. and D. Frynta. 2002. Body size, male combat and the evolution of sexual dimorphism in eublepharid geckos (Squamata: Eublepharidae). Biological Journal of the Linnean Society 76: 303314.

Kwiatkowski, M. A. and B. K. Sullivan. 2002. Geographic variation in sexual selection among populations of an iguanid lizard, Sauromalus obesus (=Ater). Evolution 56: 2039-2051.

Lappin, A. K. and J. F. Husak. 2005. Weapon performance, not size, determines mating success and potential reproductive output in the Collared Lizard (Crotaphytus collaris). American Naturalist 166: 426-436.

LeBas, N. R. 2001. Microsatellite determination of male reproductive success in a natural population of the territorial ornate dragon lizard, Ctenophorus ornatus. Molecular Ecology 10: 193-203.

Macedonia, J. M., C. S. Evans and J. B. Losos 1994. Male Anolis lizards discriminate video-recorded conspecific and heterospecific displays. Animal Behaviour 47: $1220-1223$.

Martins, E. P. and J. Lamont. 1998. Estimating ancestral states of a communicative display: a comparative study of Cyclura rock iguanas. Animal Behaviour 55: 16851706.

McMann, S. 1993. Contextual signaling and the structure of dyadic encounters in Anolis carolinensis. Animal Behaviour 46: 657-668. 
Miles, D. B., H. L. Snell and H. M. Snell. 2001. Intrapopulation variation in endurance of Galapagos lava lizards (Microlophus albemarlensis): evidence for an interaction between natural and sexual selection. Evolutionary Ecology Research 3: 795-804.

Olsson, M. 1992. Contest success in relation to size and residency in male sand lizards, Lacerta agilis. Animal Behaviour 44: 386-388.

Olsson, M. 1993. Contest success and mate guarding in male sand lizards, Lacerta agilis. Animal Behaviour 46: 408-409.

Olsson, M. 2001. No female mate choice in Mallee Dragon lizards, Ctenophorus fordiii. Evolutionary Ecology 15: 129-141.

Olsson, M. and T. Madsen. 1995. Female choice on male quantitative traits in lizards - why is it so rare? Behavioral Ecology and Sociobiology 36: 179-184.

Olsson, M. and T. Madsen. 1998. Sexual selection and sperm competition in reptiles. Pp. 503-564 in T. R. Birkhead and A. P. Moller (eds.), Sperm Competition and Sexual Selection. London. Academic Press.

Ord, T. J., D. T. Blumstein and C. S. Evans. 2001. Intrasexual selection predicts the evolution of signal complexity in lizards. Proceedings of the Royal Society London B 268: 737-744.

Paterson, A. V. 2002. Effects of an individual's removal on space use and behavior in territorial neighborhoods of brown anoles (Anolis sagrei). Herpetologica 58: 382-393.

Perry, G., K. Levering, I. Girard, and T. Garland Jr. 2004. Locomotor performance and social dominance in male Anolis cristatellus. Animal Behaviour 67: 37-47.

Peterson, C. C. and J. F. Husak. 2006. Locomotor performance and sexual selection: individual variation in sprint speed of collared lizards (Crotaphytus collaris). Copeia 2006: 216-224.

Pinto, A. C. S. 1999. Dimorfismo sexual e comportamento sexual em Tropidurus torquatus (Squamata, Tropiduridae) no Brasil Central. Unpublished M.Sc. Dissertation. Universidade de Brasília, Brazil.

Pough, F. H., R. M. Andrews, J. E. Cadle, M. L. Crump,
A. H. Savitzki, and K. D. Wells (eds.). 1998. Herpetology. New Jersey. Prentice-Hall, Inc. 577pp.

Price T. 1984. Sexual selection on body size, territory, and plumage variables in a population of Darwin's finches. Evolution 38: 327-341.

Reaney, L. T. and M. J. Whiting. 2003. Are female tree agamas (Acanthocercus atricollis atricollis) turned on by males or resources? Ethology, Ecology \& Evolution 15: $19-30$.

Robson, M. A. and D. B. Miles. 2000. Locomotor performance and dominance in male Tree Lizards, Urosaurus ornatus. Functional Ecology 14: 338-344.

Rodda, G. H. 1992. The mating behavior of Iguana iguana. Smithsonian Contributions to Zoology 534: 1-40.

Roithmair, M. E. 1994. Male territoriality and female mate selection in the dart-poison frog Epipedobates trivittatus (Dendrobatidae, Anura). Copeia 1994: 107115.

Schuett, G. W. 1997. Body size and agonistic experience affect dominance and mating success in male copperheads. Animal Behaviour 54: 213-224.

Vitt, L. J. and S. R. Goldberg. 1983. Reproductive ecology of two tropical iguanid lizards: Tropidurus torquatus and Platynotus semitaeniatus. Copeia 1983: 131-141.

Watt, M. J. and J. M. P. Joss. 2003. Structure and function of visual displays produced by male Jacky Dragons Amphibolurus muricatus, during social interactions. Brain, Behavior and Evolution 61: 172-183.

Wiederhecker, H. C., A. C. S. Pinto and G. R. Colli. 2002. Reproductive ecology of Tropidurus torquatus (Squamata: Tropiduridae) in the highly seazonal Cerrado biome of Central Brazil. Journal of Herpetology 36: 82-91.

Wikelski, M., C. Carbone and F. Trillmich. 1996. Lekking in marine iguanas: female grouping and male reproductive strategies. Animal Behaviour 52: 581596.

Zucker, N. and L. Murray. 1996. Determinants of dominance in the tree lizard Urosaurus ornatus: the relative importance of mass, previous experience and coloration. Ethology 102: 812-825. 